\title{
Polymerase Interactions with Wobble Mismatches in Synthetic Genetic Systems and their Evolutionary Implications
}

\author{
Christian B. Winiger a , Myong-Jung Kim ${ }^{\mathrm{a}, \mathrm{b}}$, Shuichi Hoshika ${ }^{\mathrm{a}, \mathrm{b}}$, Ryan W. Shaw ${ }^{\mathrm{a}, \mathrm{b}}$, \\ Jennifer D. Moses ${ }^{\mathrm{a}, \mathrm{b}}$, Mariko F. Matsuura ${ }^{\mathrm{a}, \mathrm{c}}$, Dietlind L. Gerloff ${ }^{\mathrm{a}}$, and Steven A. \\ Benner ${ }^{\mathrm{a}, \mathrm{b}^{*}}$ \\ aFoundation for Applied Molecular Evolution (FfAME), 13709 Progress Blvd. Box 7, Alachua, FL 32615, \\ USA \\ ${ }^{\mathrm{b}}$ Firebird Biomolecular Sciences LLC, 13709 Progress Blvd. Box 17, Alachua, FL 32615, USA \\ 'Department of Chemistry, University of Florida, Gainesville, FL 32611, USA
}

\section{Methods}

DNA Sequences and Oligonucleotides Synthesis

DNA sequences used for the study are: template $5^{`}$ JOE/ CTT TCG CTC GCT GCC TCG GTC CTG TTG TTX GGC GGT GGA GGC GGT, primer 5’ CCG CCT CCA CCG CC and probe 5’ AGG ACC GAG GCA GCG AGC GAA AG/ $3^{\prime}$ HB2. Primer and Probe were from IDT (Integrated DNA Technologies, Inc.). The probe was HPLC purified, while the primer for 5 ' labelling and the primer extension reaction was PAGE purified. The template containing the AEGIS building block $\mathrm{dX}$ and 5' JOE (Dichloro-dimethoxy-Fluorescein) was supplied by Firebird (www.firebirdbio.com). Ultra-mild standard phosphoramidites (Pac-dA, Ac-dC, iPr-Pac-dG, and dT), JOE phosphoramidite and CPG having standard residues were purchased from Glen Research (Sterling, VA) and AEGIS phosphoramidite (dX) were purchased from Firebird Biomolecular Sciences LLC (Alachua, FL). The template containing dX was synthesized on an ABI 394 DNA Synthesizer following standard phosphoramidite chemistry. The CPGs having oligonucleotide containing $\mathrm{dX}$ were treated with $50 \mathrm{mM}$ potassium carbonate in $\mathrm{MeOH}$ at $55^{\circ} \mathrm{C}$ for 4 hours. Then the supernatant was added to TEAA buffer. The oligonucleotide was desalted using Sep-Pac ${ }^{\circledast}$ Plus $\mathrm{C}_{1} 8$ cartridges (Waters). Finally the solution was lyophilized. The template was PAGE purified prior to use.

PAGE purification of the template and primer

The lyophilized crude product was dissolved in $90 \mu \mathrm{l}$ o.1 M TEAAc and supplemented with the same volume of $10 \mathrm{mM}$ EDTA in Formamide. The sample was loaded on a $16 \%$ preparative polyacrylamide gel (prepared form a $40 \%$ solution 19:1 Acrylamide:Bisacrylamide from Sigma) containing 7 M Urea in 1x Tris-Borate-EDTA buffer. The gel was run for $5 \mathrm{~h}$ at $70 \mathrm{~W}$. Bands were visualized under UV and cut out of the gel. Gel particles were crushed and soaked in $5 \mathrm{ml}$ o.1 M TEAA. The suspension was frozen at $-80^{\circ} \mathrm{C}$ for few h before DNA was eluted by passive diffusion over night at $4{ }^{\circ} \mathrm{C}$. Final purification was performed with Sep-Pac ${ }^{\circledast}$ Plus $\mathrm{C}_{1} 8$ cartridges (Waters) according to the manufacturer's instructions.

\section{Enzyme purification}

NiCo (a BL21 derivative from NEB) cell lines harbouring the wild type PolA plasmid were subcultured into 2XYT media containing $30 \mu \mathrm{g} / \mathrm{ml}$ kanamycin. Protein expression was induced by incubating with anhydrotetracycline (ATC) over night at $37^{\circ} \mathrm{C}$. The protein was purified by affinity chromatography using HisPur cobalt resin (Thermos Scientific). The size and purity of the enzyme was confirmed by SDS-PAGE and protein concentration was determined by the Bradford colorimetric assay (Biorad). 


\section{5'-Nuclease assay}

Template $(6.9 \mu \mathrm{M})$, primer and probe (each $6.7 \mu \mathrm{M})$ were annealed in $10 \mathrm{mM}$ Tris- $\mathrm{HCl}, \mathrm{pH} 7.5,50 \mathrm{mM} \mathrm{KCl}$ and $0.5 \mathrm{mM}$ EDTA. 5' nuclease assay was run at $50 \mu \mathrm{l}$ volume per reaction in $30 \mathrm{mM}$ Tris- $\mathrm{HCl}, \mathrm{pH} 7.5,11 \mathrm{mM}$ $\mathrm{MgCl}_{2}$, $100 \mathrm{mM} \mathrm{KCl}, 0.1 \mathrm{mg} / \mathrm{ml} \mathrm{BSA}, 50 \mathrm{mM}$ Trehalose, o.1 mM EGTA and $1 \mathrm{mM}$ freshly added DTT. Annealed template concentration was $0.134 \mu \mathrm{M}, 0.1 \mathrm{mM}$ of the indicated dNTPs (Bioline) and 55 ng protein per reaction $(10.6 \mathrm{nM}, 0.53 \mathrm{pmol})$. The reaction was run at $37^{\circ} \mathrm{C}$. Fluorescence intensity at $550 \mathrm{~nm}$ was measured in a BMG Labtech FLUORstar Omega reader upon excitation at $520 \mathrm{~nm}$. As a reference a reaction without enzyme and dNTPs as well as a reaction with enzyme but without dNTPs was run.

\section{Labelling of the primer for primer extension reaction}

30 pmol of PAGE purified primer was labelled in 1x PNK buffer in a total volume of $20 \mu \mathrm{l} .2 \mu \mathrm{l} \gamma^{32} \mathrm{P}-\mathrm{rATP}$ (5.07 $\mathrm{mCi} / \mathrm{ml}$ on due date) and $1 \mu \mathrm{l}$ of $\mathrm{T}_{4}$-PNK (1o Units, New England Biolab) was added to the mixture to initiate the phosphate transfer. The reaction was run for $30 \mathrm{~min}$ at $37^{\circ} \mathrm{C}$ before the reaction was heated to $65^{\circ} \mathrm{C}$ for 20 min. The labelled primer was purified by spin-column purification (Quiagen) and eluted in $35 \mu$ l elution buffer. The $10 \mathrm{bp}$ DNA ladder was labelled by incubating $1 \mu \mathrm{l}$ of $10 \mathrm{bp}$ DNA ladder solution (Promega) with $1 \mu \mathrm{l}$ $\gamma^{32} \mathrm{P}-\mathrm{rATP}$ and $1 \mu \mathrm{l}$ of $\mathrm{T}_{4}$-PNK in $20 \mu \mathrm{l}$ of $1 \mathrm{x}$ PNK Buffer. Incubation for $30 \mathrm{~min}$ at $37^{\circ} \mathrm{C}$ was followed by heating to $65^{\circ} \mathrm{C}$ for $20 \mathrm{~min}$ and spin-column purification (Quiagen).

\section{Primer extension}

Primer extension was performed in $30 \mathrm{mM}$ Tris- $\mathrm{HCl}, \mathrm{pH} 7.5,10 \mathrm{mM} \mathrm{MgCl}$, $100 \mathrm{mM} \mathrm{KCl}$, o.1 mg/ml BSA, 50 $\mathrm{mM}$ Trehalose, o.1 mM EGTA and $1 \mathrm{mM}$ freshly added DTT. The total reaction volume was $20 \mu \mathrm{l}$ with $0.1 \mu \mathrm{M}$ primer total, $0.0015 \mu \mathrm{M}$ of which was 5' labelled, $0.15 \mu \mathrm{M}$ Template, $0.2 \mathrm{mM}$ of the indicated dNTPs (ATP, GTP, CTP and either no additional nucleotides, dTTP, dKTP, 2-thioTTP and 4-thioTTP). Template and primer were annealed prior to the addition of dNTPs and enzyme. Enzyme was used at 71 ng per reaction. Reaction was incubated at $37^{\circ} \mathrm{C}$ for $70 \mathrm{~s}$ before the polymerase was heat-killed. $10 \mu \mathrm{l}$ of reaction mixture was mixed with same volume of loading dye. 5' labelled to bp DNA ladder (Promega) was used as standard. A $16 \%$ polyacrylamide gel ( $7 \mathrm{M}$ Urea) was run for $1.7 \mathrm{~h}$ at $70 \mathrm{~W}$. The gel was transferred to parafilm and dried for 30 min at $80{ }^{\circ} \mathrm{C}$. Radioactive spots were read on a PMI imager (BioRad) after $14 \mathrm{~h}$ of exposure time to the cassette.

\section{Evaluation of the intensity of the full length product}

The density of each radioactive spot was measured in squares with the same dimensions (Volume Tools in Quantity One 4.6.1 software). The density of the background was subtracted from the signal.

The density in $\%$ of the full length (FL) product was determined as

$$
F L[\%]=\frac{\text { density } F L}{\text { density } F L+\text { density Primer }} * 100 \%
$$




\section{Quantitative evaluation of the primer extension reaction}

Table 1. Intensity of full-length products depends on dNTP composition. Amounts of full-length product expressed as $\%$ of total radioactivity in each reaction.

\begin{tabular}{ccc} 
Lane & Nucleotides in mixture & $\begin{array}{c}\text { \% Full length } \\
\text { product }\end{array}$ \\
\hline 1 & dATP, dCTP, dGTP & 0.9 \\
2 & dATP, dCTP, dGTP, dTTP & 46.3 \\
3 & dATP, dCTP, dGTP, dKTP & 26.0 \\
4 & dATP, dCTP, dGTP, 2-ThioTTP & 1.2 \\
5 & dATP, dCTP, dGTP, 4-ThioTTP & 85.2 \\
\hline
\end{tabular}

\section{SI Figure 1. 5' nuclease assay to test incorporation of 2-ThioTTP, 4-ThioTTP and dKTP opposite of dA}

Sequence used was the following. Nucleotides to complete the strand synthesis in different reactions as indicated in the legend.

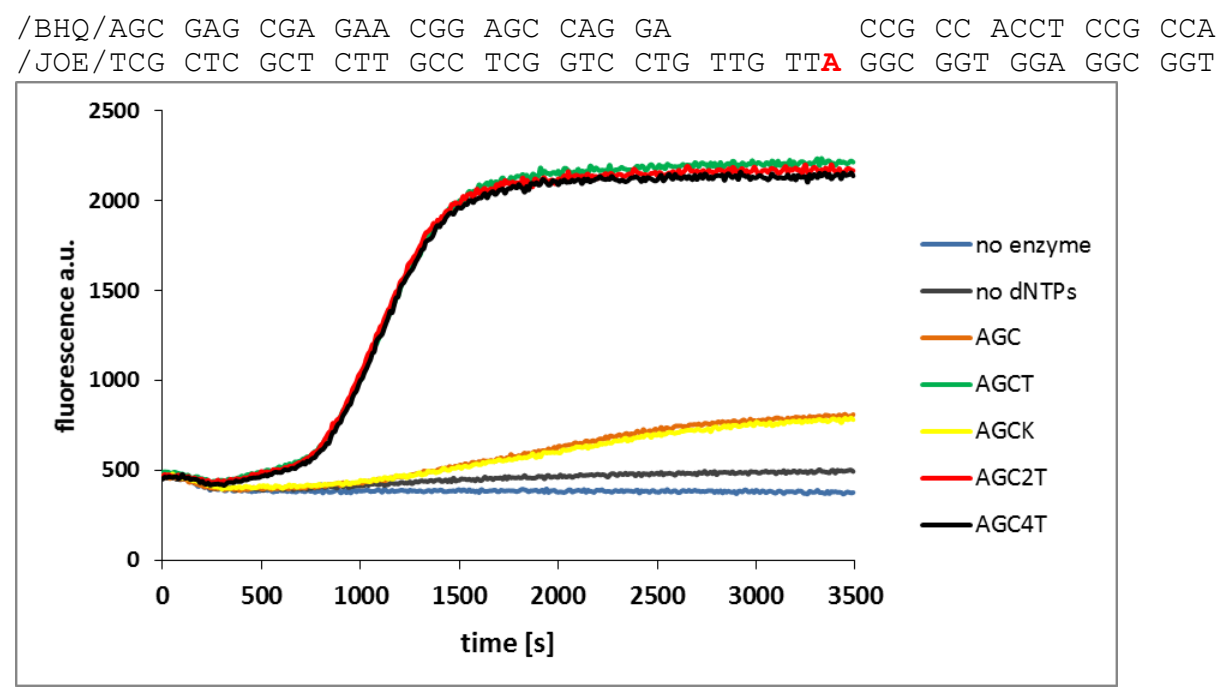

SI Figure 1 A 5' nuclease assay was performed using wt Polymerase 1 from E. coli probing a template with one single dA. Incorporation of dTTP, 2-ThioTTP and 4-ThioTTP opposite of dA occurred to equal extend. 
SI Figure2. Active side crystal structure of Polymerase A Family
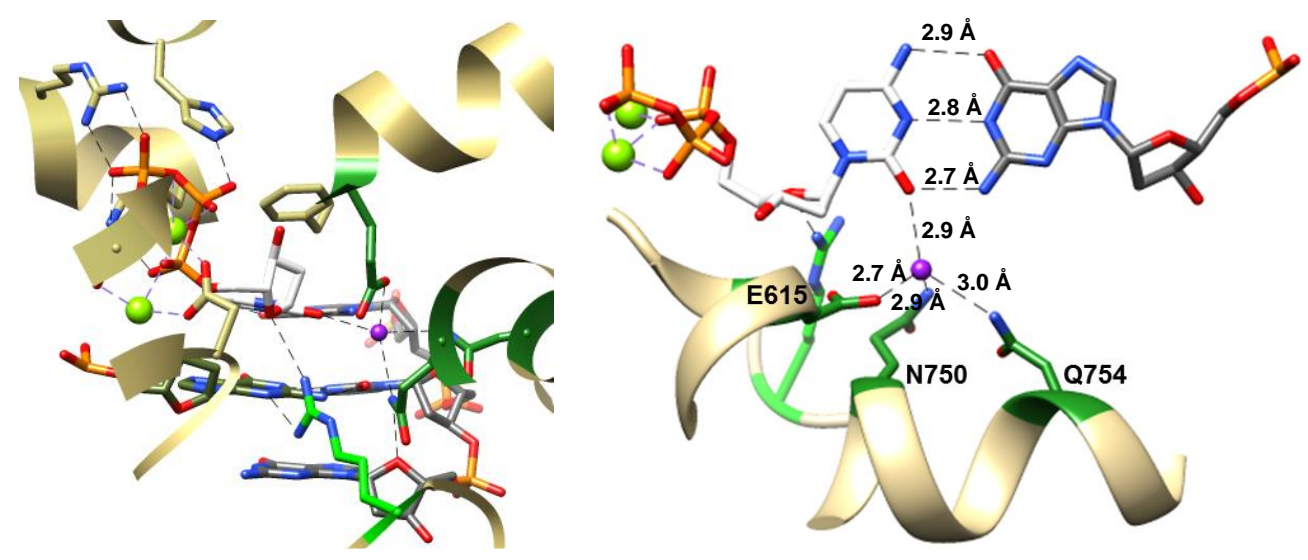

SI Figure 2. Active side crystal structure (3RTV) from a Family A polymerase from Thermus aquaticus, a homolog of the E. coli DNA polymerase 1 used here, but with a complete substrate-template-primer complex in the active site. Left. Structure of the polymerase, template, primer and incoming dCTP. Illustrated is the planar stacking of all the bases and the hydrogen contacts between the incoming base, the water molecule in the active side and the protein side chains. Right. Only one template nucleotide and the incoming triphosphate are shown for clarity. Hydrogen bond lengths between the nucleobase, the water molecule and the protein side chains are shown. Residue numbers E615, N750, Q754 in the TaqPol sequence (DPO1_THEAQ) correspond to numbers E710, N845, Q849 in the E. coli Pol 1 sequence (DPO1_ECOLI). While a structure of E. coli Pol 1 is available, that structure does not include the substrate assembly. 